\title{
USO DE QUITOSANA E EMBALAGEM PLÁSTICA NA CONSERVAÇÃO PÓS-COLHEITA DE PÊSSEGOS 'DOURADÃO’'
}

\author{
CARLOS AUGUSTO AMORIM SANTOS ${ }^{2}$, JOSALBA VIDIGAL DE CASTRO 3 , \\ ANDRESSAARAUJO PICOLI ${ }^{4}$, GLAUCO DE SOUZA ROLIM ${ }^{3}$
}

RESUMO - Este trabalho teve como objetivo avaliar a qualidade do pêssego cv. Douradão, quando aplicados tratamentos póscolheita, associada à temperatura adequada de refrigeração. Os tratamentos foram: aplicação de quitosana a 1\%; embalagem de polietileno e controle (não- tratado e sem embalagem plástica). Após serem embalados em caixas de papelão e armazenados a $3^{\circ} \mathrm{C} e$ $90 \%$ UR, durante 14; 21 e 28 dias, foram transferidos para condições- ambiente, permanecendo por 3 dias. Com o polietileno, houve menor perda de massa dos frutos durante o armazenamento; no entanto, verificou-se aumento na incidência das podridões na fase de comercialização. A quitosana não foi eficiente como protetivo contra a perda de massa, porém reduziu a incidência de podridões. Foi constatado o dano fisiológico causado pelo frio, denominado de lanosidade nos pêssegos, após 21 dias de refrigeração e mais 3 dias de comercialização, não tendo influência dos tratamentos realizados. Se o consumo dos pêssegos 'Douradão' for imediato à saída da câmara fria, o período de conservação dos frutos é de 21 dias (podridão zero), com destaque para a embalagem de polietileno, que reduziu a perda de massa. Considerando a avaliação após a comercialização simulada, o período de vida útil dos frutos é restrito aos 14 dias, a $3^{\circ} \mathrm{C}$, seguido de 3 dias em condições-ambiente devido à posterior ocorrência de lanosidade e podridão-parda.

Termos para Indexação: Prunus persica, qualidade do fruto, armazenamento, polietileno, dano pelo frio.

\section{EFFECTS OF CHITOSAN AND FILM PACKAGING ON QUALITY OF PEACHES AFTER COLD STORAGE}

\begin{abstract}
The effects of chitosan treatment and modified atmosphere packaging (MAP) on shelf life of peaches cv. Douradão were evaluated. Chitosan, a natural biodegradable compound, has been proved to control numerous post harvest diseases. It extends the shelf life of treated fruit by reducing water loss. Storage life of peaches has been extended using MAP during cold storage. Fruits were dipped in $1 \%$ chitosan solution. One group of fruits was sealed in polyethylene bags. Peaches were stored at $3{ }^{\circ} \mathrm{C}$ and $90 \% \mathrm{RH}$. Fruits were transferred to room temperature for 3 days to ripen. Quality parameters (soluble solids, acidity, ratio, firmness, pulp and skin color) and losses (weight, wooliness incidence and rots) were determined. MAP reduced fruit weight loss during storage but increased decay incidence at room temperature. Chitosan treatment was effective in brown rot reduction however showed detrimental effect on fruit appearance. Treated and untreated peaches showed woolliness after 21 days of cold storage plus 3 days at room temperature. The desirable quality was retained up to 14 days of storage.
\end{abstract}

Index Terms: Prunus persica, cold storage, polyethylene, coating, chilling injury.

\section{INTRODUÇÃO}

Devido à sua perecibilidade, os pêssegos, desde a colheita até a comercialização, apresentam elevadas perdas. Dentre os principais fatores que limitam o armazenamento e a comercialização de pêssegos, estão as podridões pós-colheita, a elevada desidratação, a perda de firmeza de polpa e os danos pelo frio durante a fase de transporte e/ou armazenamento refrigerado (Kluge et al., 1997).

A ocorrência de danos pós-colheita em pêssegos é considerada uma importante causa de desvalorização do produto por ocasião da comercialização. Martins et al. (2006) quantificaram esses danos no mercado atacadista de São Paulo. Nesta pesquisa, os gêneros fúngicos de ocorrência mais freqüente foram Monilinia (podridão-parda), Rhizopus (podridão-mole) e Cladosporium. Constatou-se que as variedades comercializadas em maior volume, Aurora, Chiripá, Dourado, Douradão, IAC e Ouromel, não apresentaram diferenças significativas na incidência de doenças (Martins et al., 2006). De acordo com Almeida (2006), os pêssegos 'Douradão'foram eleitos como os melhores pelos atacadistas, pois apresentaram as melhores características qualitativas. Em outra avaliação de perdas por doenças, na safra de 2004, Bassetto (2006) constatou 51\% dos pêssegos com sintomas de podridão-parda no pedúnculo do fruto, e $24 \%$ apresentavam sintomas no fruto todo. Em 2005, a incidência decaiu para $19 \%$ e $6 \%$, respectivamente, devido a melhorias no manuseio pós-colheita.

A quitosana possui propriedade antifúngica e, por ser um polissacarídeo natural, derivado da quitina (extraída da carapaça de crustáceos), pode ser um substituto dos atuais fungicidas, altamente nocivos ao ambiente e à saúde humana. Devido à sua capacidade de formar um recobrimento

'(Trabalho 069-07). Recebido em:21-03-2007. Aceito para publicação em; 10-10-2007. Parte da dissertação do primeiro autor, para obtenção do título de Mestre em Agricultura Tropical e Subtropical - IAC

${ }^{2}$ Aluno da PG-IAC, Caixa postal 28, CEP 13012-970, Campinas-SP. carlos.santos@uisanet.com.br

${ }^{3}$ Pesquisador, Dr, Centro de P \& D de Ecofisiologia e Biofísica, IAC. Caixa postal 28, CEP 13012-970, Campinas-SP. E-mails:josalba @iac.sp.gov.br; rolim@iac.sp.gov.br

${ }^{4}$ Aluna da PG ESALQ/USP, Piracicaba-SP. aapicoli@esalq.usp.br

Rev. Bras. Frutic., Jaboticabal - SP, v. 30, n. 1, p. 088-093, Março 2008 
semipermeável, a quitosana prolonga a vida pós-colheita, minimizando a taxa de respiração e reduzindo a perda d'água de frutos, como morango e manga (Bautista-Baños et al., 2006).

Li \& Yu (2000) constataram que o tratamento com quitosana (5 ou $10 \mathrm{mg} / \mathrm{mL})$ foi efetivo na redução da podridãoparda em pêssegos em relação ao controle. Também apresentou efeito benéfico na manutenção da firmeza, após 12 dias, a $23^{\circ} \mathrm{C}$. No trabalho de Bassetto (2006), os pêssegos 'Tropic Beauty', tratados com quitosana a $1 \%$, apresentaram menor severidade $\mathrm{e}$ incidência de doenças do que os frutos da testemunha, porém ainda esses valores foram bastante elevados.

A lanosidade é um fator de considerável importância econômica, já que é um dos primeiros sintomas de dano pelo frio, limitante do potencial de armazenagem. É considerada como sério problema chileno de exportação para mercados, no qual o período de transporte é de 12 a 14 dias (Luchsinger, 2000). Como muitas fisiopatias, a lanosidade, caracterizada por polpa seca e farinhenta, perda de sabor, brilho e firmeza, e ausência de suculência, é muito difícil de se determinar externamente. $\mathrm{O}$ sintoma não se manifesta durante ou imediatamente à saída do armazenamento, porém o faz no período de amadurecimento ou comercialização e se manifesta somente ao partir o fruto. Trabalho realizado por Bron et al. (2002), com pêssegos 'Aurora-1' e 'Dourado-2', armazenados a $0 ; 3$ e $6^{\circ} \mathrm{C}$, por $7 ; 14 ; 21$ e 28 dias, mostrou resposta diferenciada das cultivares. Frutos de 'Aurora1 ' não apresentaram sintomas em nenhuma das temperaturas. Os pêssegos 'Dourado-2' apresentaram sintomas de lanosidade após serem removidos do armazenamento $\left(7\right.$ dias a $3^{\circ} \mathrm{C}$ ou 14 dias a $0^{\circ} \mathrm{C}$ ) e mantidos por dois dias em temperatura ambiente.

Kluge et al. (1999) avaliaram a qualidade de pêssegos 'Flordaprince', em diferentes tipos de embalagens plásticas (PVC, polietileno - 20 e $70 \mu \mathrm{m}$ de espessura), refrigerados por 14 e 28 dias e, após cada período, mantidos a $25^{\circ} \mathrm{C}$, por dois dias. Aos 14 dias, a perda de massa do controle (sem embalagem) foi mais do que dez vezes superior à verificada nos tratamentos com filmes plásticos. Não ocorreu lanosidade após este período de armazenamento. O polietileno manteve mais alta a firmeza da polpa dos frutos durante 14 dias de refrigeração. Após 28 dias de conservação, os pêssegos-controle apresentavam-se completamente murchos e impróprios para a comercialização. O aparecimento da lanosidade demonstrou que a sensibilidade dessa cultivar é alta em armazenamento prolongado, mesmo com a utilização da embalagem plástica.

Nunes et al. (2004) avaliaram a eficiência de sacos de polietileno $(60 \mu \mathrm{m}$ de espessura) na vida pós-colheita de pêssegos 'Aurora-2' mantidos por 10 dias, a $9 \pm 1^{\circ} \mathrm{C}$ e $90 \pm 5 \%$ UR. O polietileno foi mais eficiente, comparado ao controle, em reduzir a perda de massa dos frutos $(0,47 \%)$ por promover maior umidade relativa, reduzindo a transpiração dos frutos. Observouse que a acidez total titulável e os sólidos solúveis totais não foram influenciados pelos fatores atmosfera modificada e período de armazenamento.

O objetivo da pesquisa foi avaliar a efetividade da quitosana e da embalagem de polietileno associada à refrigeração na conservação da qualidade de pêssegos 'Douradão'.

\section{MATERIAL E MÉTODOS}

A cultivar IAC Douradão (IAC 6782-83), lançada em 1998, é F1 de 'Dourado-1', em polinização aberta, e F2 do cruzamento 'Tutu' x 'Maravilha', foi batizado de 'Douradão' por sua similaridade aos pêssegos da série 'Dourado'. Apresenta frutos bem grandes, formato globoso-oblongo, atraente e de coloração externa até $90 \%$ vermelho-estriada, sobre fundo amarelo-claro. A polpa amarela mostra-se espessa, firme, fibrosa, medianamente suculenta e sem aderência ao caroço. O sabor doce-acidulado apresenta-se bem equilibrado e agradável (Barbosa et al., 2000). Os frutos foram colhidos em meados de outubro/2005, em pomar comercial situado em Atibaia-SP, selecionados, descartando-se aqueles com lesões ou coloração inadequada, procurando-se uniformizar o estádio de maturação.

Os pêssegos foram numerados, pesados e submetidos aos seguintes tratamentos: a - frutos sem tratamento (controle); $\mathrm{b}$ - frutos acondicionados em embalagens de polietileno de baixa densidade com 0,06 mm de espessura; c - frutos imersos em solução de quitosana (Cyrbe do Brasil) a $1 \%$, com posterior secagem natural. Os frutos foram acondicionados em caixas de papelão apropriadas para a comercialização de pêssegos e armazenados a $3^{\circ} \mathrm{C}$, com $90-95 \%$ de umidade relativa. Esse período foi denominado armazenamento. Para simular o período de comercialização, os frutos sob refrigeração, após 14; 21 e 28 dias, foram transferidos à condição ambiente $\left(24^{\circ} \mathrm{C}\right.$ e UR $\left.70 \%\right)$, onde permaneceram durante três dias. Nessa etapa, também conhecida como vida de prateleira, as embalagens plásticas foram removidas.

As avaliações realizadas foram: a) perda de massa, realizada através da pesagem individual dos frutos e o cálculo das perdas de massa dos pêssegos dos diferentes tratamentos e épocas de amostragem, expresso em \%; b) coloração da casca e da polpa: determinada com um colorímetro da Minolta. Avaliaramse os valores de L (luminosidade), a [quantidade de verde (-) a vermelho $(+)$ ] e b [de azul (-) a amarelo $(+)]$. As colorações também foram expressas pela cromaticidade (Croma) e ângulo de cor (h), onde o valor 0 é correspondente à cor vermelha, 90 corresponde à cor amarela, 180 à cor verde (McGuirre, 1992); c) firmeza dos frutos foi determinada com o penetrômetro FT 327, com ponteira de $8 \mathrm{~mm}$, em dois pontos opostos na região equatorial, e os resultados expressos em N. Foram determinadas as percentagens de frutos com sintomas da podridão-parda. A aparência interna dos frutos, para verificar a ocorrência de lanosidade, foi observada quando os frutos foram abertos para avaliação durante a etapa de comercialização simulada. Os teores de sólidos solúveis foram analisados com refratômetro Shibuya, e os resultados expressos em ${ }^{\circ}$ Brix, e o valor da acidez titulável da polpa foi obtido de $10 \mathrm{~g}$ do homogenato, pesado, diluído em 90 $\mathrm{ml}$ de água destilada e titulado com solução de hidróxido de sódio $(\mathrm{NaOH})$ a $0,1 \mathrm{~N}$, e o resultado expresso em gramas de ácido málico por 100 gramas de polpa. Utilizou-se do delineamento inteiramente casualizado, em parcelas subdivididas. A parcela experimental constou de seis frutos. Para cada característica avaliada, foi realizada a Análise de Variância, teste de Tukey, ao 
nível de 5\% de significância, utilizando-se do programa Statistica 6.0 .

\section{RESULTADOS E DISCUSSÃO}

$\mathrm{Na}$ colheita, a massa fresca média dos pêssegos foi de $111,06 \mathrm{~g}$, que está de acordo com as observações de Barbosa et al. (2000), que obtiveram massa média dessa cultivar de $160 \mathrm{~g}$, onde cerca de $10 \%$ dos frutos apresentam massas entre $201 \mathrm{e}$ $350 \mathrm{~g}, 40 \%$ entre 141 e $200 \mathrm{~g}, 40 \%$ entre 101 e $140 \mathrm{~g}$ e $10 \%$ entre 70 e $100 \mathrm{~g}$.

A perda de massa apresentada pelos frutos ao longo do período de armazenamento refrigerado e ambiente pode ser observada na Figura 1. No armazenamento, os pêssegos embalados em polietileno obtiveram significativamente menor perda de massa, mantendo praticamente a mesma massa inicial dos frutos. Verificou-se que a utilização da atmosfera modificada no armazenamento é um meio de minimizar o déficit de pressão de vapor (DPV) entre os frutos e a atmosfera que os circunda e, conseqüentemente, limitar a perda d'água destes por transpiração, reduzindo a perda de massa. Esses efeitos favoráveis na manutenção da qualidade dos frutos foram observados em pêssegos 'Flordaprince' (Kluge et al., 1999) e em 'Aurora-2' (Nunes et al., 2004). Na comercialização simulada de 3 dias, após os pêssegos serem retirados da embalagem, a perda média de massa foi de $4,3 \%$. Os pêssegos embalados em polietileno após o armazenamento refrigerado por 14 e 21 dias, seguido de 3 dias em condições-ambiente, obtiveram conseqüentemente menor perda de massa total $(4,5 \%)$, mostrado na Figura $1 \mathrm{~b}$. Esses resultados estão condizentes com os determinados por KLUGE et al. (1999) durante comercialização simulada de pêssegos 'Flordaprince'.

Ao contrário do que se esperava, a quitosana não teve efeito protetor contra a perda de umidade dos frutos que devido à sua habilidade de formar uma película semipermeável, pode modificar a atmosfera interna e diminuir as perdas por transpiração e desidratação dos frutos. Os frutos tratados com quitosana apresentaram significativamente as maiores perdas de massa após 14; 21 e 28 dias de armazenamento refrigerado (Figura 1a), mostrando sinais visíveis de desidratação que comprometeram o aspecto externo do fruto. Essa reação adversa na epiderme do fruto pode ter sido ocasionada pelos reagentes químicos utilizados na extração e formulação comercial da quitosana, como alertam Assis \& Leoni (2003). Nos pêssegos tratados com quitosana, a perda média de massa foi de 5,4\% durante a comercialização simulada. As perdas de massas totais para este tratamento foram bastante elevadas porque se situaram entre 20 e $31 \%$, após 14 e 28 dias de armazenamento, seguido de 3 dias em condições-ambiente (Figura 1b).

Na colheita, a luminosidade da casca dos pêssegos apresentou média de 44,06. Os frutos, inicialmente, apresentaram na casca quantidades da cor vermelha (valor de a) e da cor amarela (valor de b), respectivamente, de 19,71 e 15,75. A cromaticidade e o ângulo de cor (h) da casca dos frutos foram de 26,53 e 36,33, respectivamente.
A mudança na coloração, que ocorre ao longo do período de maturação e amadurecimento do fruto, sem dúvida, é o critério mais utilizado pelo consumidor para julgar sua maturidade, como também confere atratividade a este, e é resultante da diminuição da concentração de clorofila (cor verde) em favor da concentração de carotenóides (aumento nos valores de a e b).

Não houve efeito significativo entre as épocas de avaliação (refrigeração e comercialização) na variação dos valores de cor externa. Em relação aos tratamentos, os valores de luminosidade (L) foram maiores nos pêssegos embalados em polietileno, que transpiraram menos. Os frutos-controle e tratados com quitosana apresentaram significativamente menor luminosidade, representando que a casca estava mais escura do que as dos frutos embalados em polietileno (Tabela 1). Os valores de a (cor vermelha) e de C (cromaticidade) foram menores nos pêssegos tratados com quitosana. Os frutos em polietileno apresentaram maiores valores de $b$ (cor amarela), que refletiram em maiores valores de ângulo, predominando o amarelo sobre o vermelho (Tabela 1). Menor valor de h (ângulo de cor) na casca dos pêssegos-controle mostra que a cor vermelha está predominando em relação ao amarelo, fato que, para essa cultivar, é um dos seus atrativos, como destaca Almeida (2006). Bron et al. (2002) constataram decréscimo no valor de $\mathrm{h}$ em pêssegos 'Dourado-2' e 'Aurora-1' armazenados a $3^{\circ} \mathrm{C}$ e mantidos dois dias em temperatura ambiente.

$\mathrm{Na}$ colheita, a polpa dos pêssegos apresentou luminosidade de 65,53, o ângulo de cor mostrou que a coloração interna dos frutos estava amarela, com poucos tons de vermelho $(\mathrm{h}-86,74)$ e cromaticidade de 51,80 . A luminosidade (L) da polpa de pêssegos mostra que houve diferença significativa entre os tratamentos, após comercialização simulada (Tabela 1). Os frutoscontrole apresentaram menor valor de L, que indica que a polpa estava mais escurecida em relação aos pêssegos embalados em polietileno ou tratados com quitosana. Fernández-Trujillo et al. (1998) relatam decréscimos, comparados aos valores obtidos na colheita, durante armazenamento refrigerado nos valores de $\mathrm{C}$ (cromaticidade) e b (quantidade de amarelo), e pequeno aumento no valor de a (cor vermelha) da polpa de pêssegos cultivar Sudanell-1. Essas variações de cor foram associadas a sintomas de dano pelo frio, fato que ocorreu neste trabalho (Tabela 1).

A ausência visual de suculência, que é um sintoma típico da lanosidade, foi observada nos pêssegos 'Douradão' durante a etapa de comercialização simulada. Há grande variação entre as diferentes seleções e/ou cultivares de pêssego em relação à sensibilidade a esse dano. Entre muitos fatores, a genética exerce grande influência na ocorrência dos sintomas que são desencadeados pela temperatura e pelo tempo de armazenamento (Lurie \& Crisosto, 2005). A sensibilidade do 'Douradão'ao armazenamento refrigerado pode ser explicada pelo fato de essa cultivar ser originada do 'Dourado-1'(IAC 976-6). Essa cultivar é precoce e de caroço solto, cujos progenitores 'Tutu' e 'Maravilha' são pêssegos de polpa branca e delicada. Crisosto et al. (1999) relatam que as cultivares de pêssegos de caroço solto são mais sensíveis em relação aos de caroço preso. Bron et al. (2002) mostraram que pêssegos 'Dourado-2' (mesmas características de Dourado-1) são sensíveis ao armazenamento porque os frutos 
apresentaram sintoma de lanosidade, causados pela ausência visual de suculência e queda brusca da firmeza, após sete dias de armazenamento a $3^{\circ} \mathrm{C}$, seguido de dois dias em condiçõesambiente. Na cultivar Douradão, foi constatado esse distúrbio fisiológico causado pela baixa temperatura de armazenamento, em todos os pêssegos, com diferentes tratamentos, a partir dos 21 dias de armazenamento seguidos de três dias em condiçõesambiente. Não se constataram diferenças na severidade da lanosidade devido a efeito de tratamentos.

A firmeza de polpa média dos pêssegos, no momento da colheita, foi 41,68 N, estando de acordo com Almeida (2006), que obteve 45,60 N nos frutos de Douradão. Após o terceiro dia dos frutos colhidos e mantidos diretamente em condições-ambiente, o valor médio de firmeza da polpa obtida, $2,45 \mathrm{~N}$, indicou que os pêssegos estavam bastante amolecidos. No presente estudo, não houve efeito dos tratamentos na manutenção da firmeza da polpa após armazenamento refrigerado, seguido de 3 dias em condições-ambiente. Os valores obtidos foram próximos a 4,90 $\mathrm{N}$ (Figura 2), indicando que os pêssegos estavam muito moles, comprometendo a qualidade para o consumidor. Pode-se notar a acentuada queda de firmeza dos pêssegos mesmo após 14 dias de armazenamento refrigerado e exposto por três dias em condições-ambiente. Bron et al. (2002) também observaram acentuada queda da firmeza em pêssegos 'Dourado-2', cultivar sensível ao dano pelo frio, com 14 dias de armazenamento.

A incidência de Monilinia fruticola em pêssegos foi constatada a partir dos 21 dias de armazenamento refrigerado (Figura 3). Após 28 dias de armazenamento refrigerado, mais de $20 \%$ dos frutos apresentaram sintomas de podridão-parda na saída da câmara fria. Nos frutos- controle e tratados com quitosana, as perdas devidas à podridão foram inferiores a $10 \%$ (Figura 3 ). A doença desenvolveu-se mais quando os frutos foram transferidos às condições-ambientes (Figura 3). Esse fato ocorreu principalmente nos pêssegos embalados em polietileno, no qual durante a etapa de refrigeração foi observada a ocorrência de condensação de água, resultante do processo de transpiração dos frutos. Esse acúmulo de umidade pode ter favorecido o desenvolvimento do patógeno e, conseqüentemente, a incidência de Monilinia fruticola. Nos frutos embalados com polietileno, após 21 e 28 dias de armazenamento refrigerado, seguido de 3 dias de comercialização simulada, houve alta incidência da podridãoparda, que comprometeu a qualidade de $80 \%$ dos pêssegos (Figura 3). Os frutos tratados com quitosana, devido possivelmente às propriedades antifúngicas, apresentaram menor incidência do patógeno, em média ocorreu $16,7 \%$, após 21 dias de armazenamento refrigerado, seguido de 3 dias em condiçõesambiente (Figura 3). Nos trabalhos de Li \& Yu (2000), também com pêssegos, e de Bassetto (2006), com a cultivar Tropic Beauty, foi constatado, respectivamente, que a quitosana controlou satisfatoriamente e reduziu parcialmente a incidência de doenças. Se o consumo dos pêssegos 'Douradão' for imediato à saída da câmara fria, o período de conservação dos frutos é de 21 dias (podridão zero), com destaque para a embalagem de polietileno, que reduziu a perda de massa. Considerando a avaliação após a comercialização simulada, o período de vida útil dos frutos é restrito aos 14 dias a $3{ }^{\circ} \mathrm{C}$, seguido de 3 dias em condições- ambiente devido à posterior ocorrência de lanosidade e podridãoparda.

O teor de sólidos solúveis obtidos na colheita dos pêssegos foi de $8,80^{\circ}$ Brix. Esse valor está de acordo com o valor mínimo, que é de $8^{\circ}$ Brix, para os pêssegos colhidos não serem considerados imaturos pelo Regulamento Técnico de Identidade e Qualidade do Pêssego e Nectarina (Hortibrasil, 2006). Após serem mantidos diretamente em condições-ambiente, os pêssegos apresentaram sólidos solúveis com valores médios de $9,20^{\circ}$ Brix. Os pêssegos-controle, após 14; 21 e 28 dias de armazenamento, seguido de 3 dias de comercialização, apresentaram valor médio de $9,53^{\circ}$ Brix. Os pêssegos embalados em polietileno, após 14 e 21 dias de armazenamento, seguido de 3 dias em condições-ambiente, mantiveram valores praticamente idênticos aos obtidos na colheita. Com quitosana, após 14; 21 e 28 dias de armazenamento, seguido de 3 dias de comercialização, o valor médio nos frutos foi de $10,8^{\circ}$ Brix. Essa maior concentração de sólidos pode ser devida à perda d'água por transpiração (Figura 1).

A acidez titulável dos pêssegos não apresentou diferenças significativas entre os tratamentos durante o período de armazenamento e comercialização, que se mantiveram com teor de acidez da ocasião da colheita, que foi de $0,20 \%$. Resultado similar para o teor de acidez foi obtido por Almeida (2006) em pêssegos dessa cultivar produzidos na região de ParanapanemaSP. Em todos os tratamentos, a relação sólidos solúveis/acidez apresentou valor maior que 25, sugeridos por Deshpande \& Salunkle (1964) para os pêssegos com ótima maturidade para consumo. Almeida (2006) obteve valor médio de 49,12 na relação SS/A em pêssegos dessa cultivar, condizentes com os resultados obtidos no presente trabalho.

TABELA 1 - Valores médios de a, b, C e h de cor da casca e da polpa de pêssegos 'Douradão' com diferentes tratamentos. Campinas-SP, 2005.

\begin{tabular}{cccccc}
\hline & \multicolumn{5}{c}{ Cor de casca } \\
\cline { 2 - 6 } Tratamento & $\mathrm{L}$ & $\mathrm{a}$ & $\mathrm{b}$ & $\mathrm{C}$ & $\mathrm{h}$ \\
\hline Controle & $45,47 \mathrm{~b}$ & $22,21 \mathrm{a}$ & $19,10 \mathrm{~b}$ & $31,19 \mathrm{ab}$ & $37,41 \mathrm{~b}$ \\
Quitosana & $45,78 \mathrm{~b}$ & $18,94 \mathrm{~b}$ & $19,65 \mathrm{ab}$ & $29,51 \mathrm{~b}$ & $41,51 \mathrm{ab}$ \\
Polietileno & $48,19 \mathrm{a}$ & $21,15 \mathrm{ab}$ & $22,23 \mathrm{a}$ & $32,28 \mathrm{a}$ & $43,04 \mathrm{a}$ \\
\hline \multicolumn{5}{c}{ Cor da polpa } \\
Tratamento & $\mathrm{L}$ & $\mathrm{a}$ & $\mathrm{b}$ & $\mathrm{C}$ & $\mathrm{h}$ \\
\cline { 2 - 6 } Controle & $65,60 \mathrm{~b}$ & $9,57 \mathrm{~b}$ & $46,18 \mathrm{a}$ & $47,89 \mathrm{a}$ & $77,51 \mathrm{a}$ \\
Quitosana & $67,30 \mathrm{a}$ & $12,89 \mathrm{a}$ & $42,85 \mathrm{~b}$ & $44,31 \mathrm{~b}$ & $72,76 \mathrm{~b}$ \\
Polietileno & $69,31 \mathrm{a}$ & $8,96 \mathrm{~b}$ & $47,65 \mathrm{a}$ & $48,50 \mathrm{a}$ & $79,37 \mathrm{a}$ \\
\hline
\end{tabular}

L: luminosidade; a: coloração verde-vermelha; b: coloração azul-amarela; C: cromaticidade; h: ângulo de cor coloração verde, amarela, vermelha Médias seguidas pela mesma letra na coluna não diferem pelo Teste de Tukey, a $5 \%$ de probabilidade. 


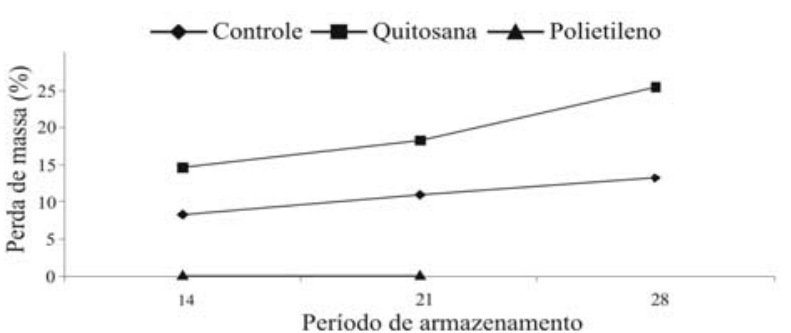

(a)

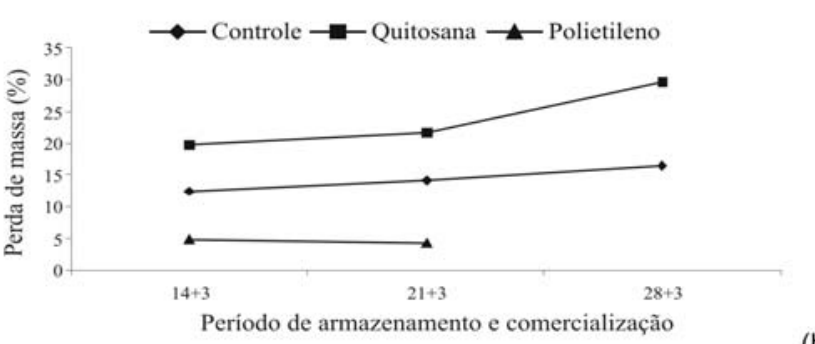

(b)

FIGURA 1 - Perda de massa de pêssegos 'Douradão' com diferentes tratamentos, após 14; 21 e 28 dias de armazenamento refrigerado (a) e seguido de 3 dias de comercialização simulada (b). Campinas-SP, 2005.

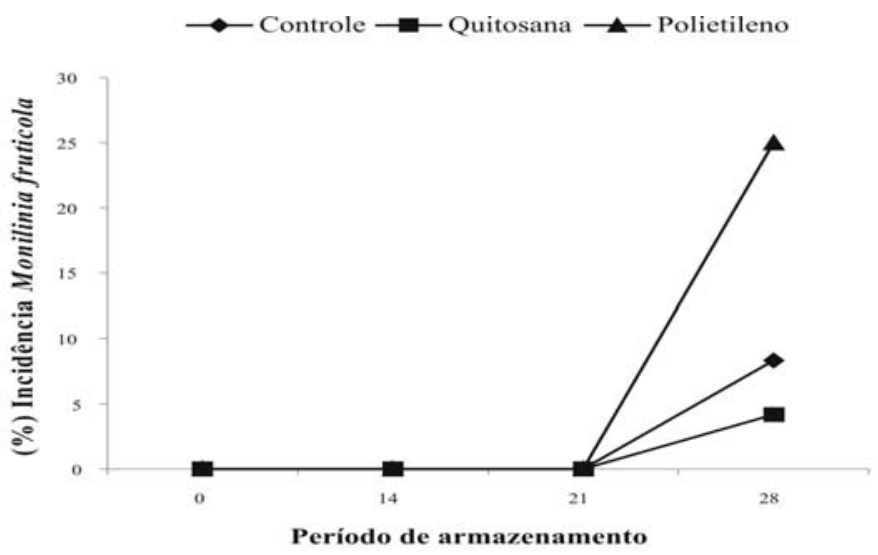

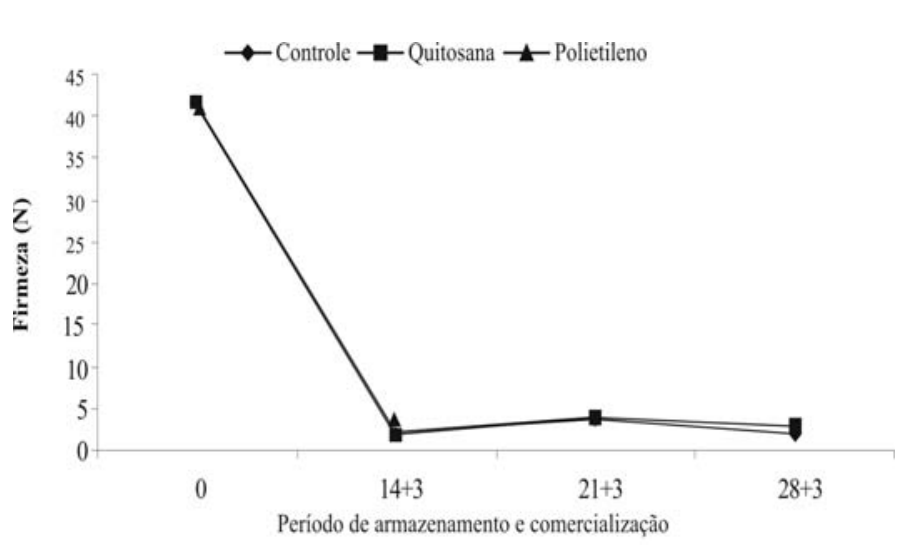

FIGURA 2 - Firmeza da polpa de pêssegos 'Douradão' durante armazenamento refrigerado, por 14; 21 e 28 dias, seguido de 3 dias de comercialização simulada. Campinas - SP, 2005

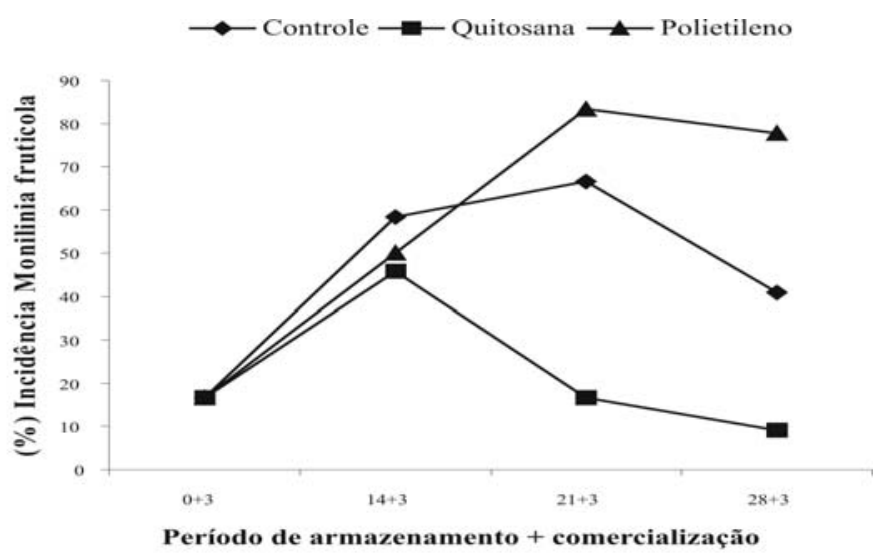

FIGURA 3 - Incidência de Monilinia fruticola em pêssegos 'Douradão' durante armazenamento refrigerado e durante período de comercialização (3 dias), Campinas-SP, 2005.

\section{CONCLUSÕES}

1-A utilização da embalagem plástica associada ao armazenamento refrigerado controlou efetivamente a perda de massa, porém os pêssegos revestidos com quitosana apresentaram maior perda de massa, e sintomas de desidratação foram vistos.

2-Os pêssegos não apresentaram incidência de podridões até 21 dias de armazenamento; entretanto, quando se transferiu o fruto para condições-ambiente, a ocorrência de podridão- parda limitou a vida útil dos frutos. Notou-se efeito da quitosana no controle de podridões.
3-Ocorreu o distúrbio fisiológico de lanosidade, que foi constatado em todos os frutos após 21 dias de armazenamento e 3 dias de condições-ambiente.

4-Considerando todos os fatores avaliados, o período de vida útil dos pêssegos foi de 14 dias, a $3{ }^{\circ} \mathrm{C}$, seguido de 3 dias em condições-ambiente. 


\section{REFERÊNCIAS}

ALMEIDA, G.V.B. Características qualitativas de pêssegos produzidos em Paranapanema-SP, safra 2005, e sua valoração no mercado atacadista de São Paulo. Jaboticabal, 2006. $66 \mathrm{f}$. Dissertação (Mestrado em Agronomia) - Universidade Estadual Paulista, Faculdade de Ciências Agrárias e Veterinárias, 2006.

ASSIS, O.B.G.; LEONI, A.M. Filmes comestíveis de quitosana. Revista Biotecnologia, Ciência e Desenvolvimento, Uberlândia, n. 30, p.33-38, 2003.

BARBOSA, W.; OJIMA, M.; CAMPO DALL'ORTO, F. A. Pêssego 'Douradão'. In: Donadio, L.C (Ed.). Novas variedades brasileiras de frutas. Jaboticabal: Sociedade Brasileira de Fruticultura, 2000. p.176-177.

BASSETTO, E. Quantificação de danos ao longo da cadeia produtiva de pêssegos e avaliação de métodos alternativos de controle de doenças pós-colheita. Piracicaba, 2006. 126f. Tese (Doutorado em fitopatologia) - Escola Superior de Agricultura Luiz de Queiroz, 2006.

BAUTISTA-BAÑOS, S.; HERNÁNDEZ-LAUZARDO, A.N.; VELÁZQUEZ-DEL-VALLE, M.G; HERNÁNDEZ-LÓPEZ, M.; BARKA, E.A.; BOSQUEZ-MOLINA, E.; WILSON, C.L. Chitosan as a potencial natural compound to control pre and postharvest diseases of horticultural commodities. Crop Protection, v. 25, p. 108-118,2006.

BRON, I.U.; JACOMINO, A.P.; APPEZATO-DA-GLÓRIA, B. Alterações anatômicas e físico-químicas associadas ao armazenamento refrigerado de pêssegos 'Aurora-1' e 'Dourado2'. Pesquisa Agropecuária Brasileira. Brasília, v.37, n.10, p.1349$1358,2002$.

CRISOSTO, C.H.; MITCHELL, F.G.; JU, Z. Susceptibility to chilling injury of peach, nectarine, and plum cultivars grown in California. HortScience, v. 36, n.6, p. 1116-1118, 1999.

DESHPANDE, P.B.; SALUNKHE, D.K. Effects of maturity and storage on certain biochemical changes in apricot and peaches. Food Technology, v.18, n.8, p. 85-88, 1964.
FERNÁNDEZ-TRUJILLO, J.P.; MARTÍNEZ, J.A.; ARTÉS, F. Efectos de la conservación frigorífica en la fisiología y calidad del melocotón Sudanell. Food Science and Technology International, v.4, n. 4, p. 245-255, 1998.

HORTIBRASIL. Programa Brasileiro para a Modernização da Horticultura. Classificação. Disponível em: www.hortibrasil.org.br Acesso em: 25 maio 2006.

KLUGE, R.A.; NACHTIGAL, J.C.; FACHINELLO, J.C.; BILHALVA, A.B. Fisiologia e manejo pós-colheita de frutas de clima temperado. Pelotas: Editora UFPEL, 1997. 163 p. KLUGE, R.A.; SCARPARE FILHO, J.A.; JACOMINO, A.P.; MARQUES, C. Embalagens plásticas para pêssegos 'flordaprince' refrigerados. Scientia Agricola, Piracicaba, v.56, n.4, p.843-850, 1999.

LI, H.; YU, T. Effect of chitosan on incidence of brown rot, quality and physiological atributes of postharvest peach fruit. Journal of the Science of Food and Agriculture, v.81, p. 269-274, 2000.

LUCHSINGER, L.L. Control de fisiopatías en frutos de carozo (hueso). In: Memorias del 2 Congreso Iberoamericano de Tecnología Postcosecha y Agroexportaciones. 3er. Simposio Control de fisiopatías en frutas durante el almacenamiento en frío. Santa Fé de Bogotá: Universidad Nacional de Colombia, 2000. p. 87-93.

LURIE, S.; CRISOSTO, C.H. Chilling injury in peach and nectarine. Postharvest Biology and Technology, v. 37, p.195-208, 2005.

MARTINS, M.C.; LOURENÇO, S.A.; GUTIERREZ, A.S.D.; JACOMINO, A.P.; AMORIM, L. Quantificação de danos póscolheita em pêssegos no mercado atacadista de São Paulo. Fitopatologia Brasileira, v. 31, n1, p.5-10, 2006.

McGUIRRE, R.G. Reporting of objective color measurements. HortScience, v. 27, n. 12, p. 1254-1255, 1992.

NUNES, E.E.; VILAS BOAS, B.M.; CARVALHO, G.L.; SIQUEIRA, H.H.; LIMA, L.C.O. Vida útil de pêssegos 'Aurora-2' armazenados sob atmosfera modificada e refrigeração. Revista Brasileira de Fruticultura, Jaboticabal, v.26, n.3, p.438-440, 2004. 